\title{
Avaliação da dispersividade e resistência à compressão simples de compósitos de solo, resíduos de construção e demolição e cal hidratada
}

\author{
Evaluation of dispersibility and resistance to simple compression of soil composites, construction \\ and demolition waste and hydrated lime \\ Evaluación de la dispersabilidad y resistencia a la compresión simple de compuestos de suelo, \\ residuos de construcción y demolición y cal hidratada
}

\section{Resumo}

O solo dispersivo é um material que apresenta problemas relativos a erodibilidade por fenômeno químico, e necessita de técnicas que viabilizem a melhoria de suas características para utilização. Neste trabalho, realizou-se a aplicação de resíduo de construção e demolição (RCD) em substituição à fração de um solo dispersivo oriundo da Ilha de Itamaracá, junto a adição de cal para melhoria da dispersividade e da resistência à compressão simples (RCS). O solo e o RCD foram utilizados na produção de compósitos, em percentuais de $20 \%, 40 \%$ e $60 \%$ de RCD, ea cal hidratada adicionada em teores de 3\%, 5\% e 7\%. Foram realizados ensaios de caracterização física, química, mineralógica e mecânica, além de ensaios de erodibilidade. Os resultados indicaram que o RCD quando junto à cal, apresenta resultados superiores ao do solo, para $40 \%$ e $60 \%$ de RCD, a partir de 3\% de cal, atingindo ganhos de até $300 \%$. Assim, como na RCS, para a dispersividade, os melhores resultados se referem à ação conjunta de RCD e cal, tendo os compósitos de $40 \%$ e $60 \%$ os melhores desempenhos. Dessa forma, observa-se que é viável a melhoria da dispersividade do solo e da RCS com aplicação do RCD em substituição de parte do solo quando se adiciona à cal. Dessa forma, evidencia-se a possibilidade de melhorar as características do solo dispersivo, junto a uma aplicação para o RCD, para o qual se obtém uma destinação final correta, sendo assim, uma utilização benéfica sob o aspecto sustentável.

Palavras-chave: Solo dispersivo; Resíduo de construção e demolição; Cal.

\begin{abstract}
Dispersive soil is a material that presents problems related to erodibility due to chemical phenomena, and requires techniques that enable the improvement of its characteristics for use. In this work, construction and demolition waste (RCD) was applied to replace the fraction of a dispersive soil from the island of Itamaracá, together with the addition of lime to improve dispersion and resistance to simple compression (RCS). The soil and the RCD were used in the production of composites, in percentages of $20 \%, 40 \%$ and $60 \%$ of RCD, and the hydrated lime added in levels of $3 \%$,
\end{abstract}


$5 \%$ and $7 \%$. Physical, chemical, mineralogical and mechanical characterization tests were carried out, in addition to erodibility tests. The results indicated that the RCD when next to the lime, presents results superior to that of the soil, for $40 \%$ and $60 \%$ of RCD, from $3 \%$ of lime, reaching gains of up to $300 \%$. Thus, as in RCS, for dispersiveness, the best results refer to the joint action of RCD and lime, with composites of $40 \%$ and $60 \%$ having the best performances. Thus, it is observed that it is feasible to improve the dispersiveness of the soil and the RCS by applying the RCD to replace part of the soil when added to the lime. In this way, the possibility of improving the characteristics of the dispersive soil is evidenced, together with an application for the RCD, for which a correct final destination is obtained, thus, a beneficial use under the sustainable aspect.

Keywords: Dispersive soil; Construction and demolition waste; Lime.

\section{Resumen}

El suelo dispersivo es un material que presenta problemas relacionados con la erosionabilidad por fenómenos químicos, y requiere de técnicas que permitan mejorar sus características de uso. En este trabajo se aplicaron residuos de construcción y demolición (RCD) para reemplazar la fracción de un suelo dispersivo de la isla de Itamaracá, junto con la adición de cal para mejorar la dispersión y resistencia a la compresión simple (RCS). El suelo y el RCD se utilizaron en la producción de composites, en porcentajes de $20 \%, 40 \%$ y $60 \%$ de RCD, y la cal hidratada añadida en niveles de 3\%, 5\% y 7\%. Se realizaron ensayos de caracterización física, química, mineralógica y mecánica, además de ensayos de erosionabilidad. Los resultados indicaron que el RCD al lado de la cal, presenta resultados superiores al del suelo, para $40 \%$ y $60 \%$ de RCD, a partir del 3\% de cal, alcanzando ganancias de hasta 300\%. Así, al igual que en RCS, en cuanto a dispersividad, los mejores resultados se refieren a la acción conjunta del RCD y la cal, siendo los composites de $40 \%$ y $60 \%$ los de mejores rendimientos. Así, se observa que es factible mejorar la dispersividad del suelo y el RCS aplicando el RCD para reemplazar parte del suelo cuando se agrega a la cal. De esta forma, se evidencia la posibilidad de mejorar las características del suelo dispersivo, junto con una aplicación del RCD, para lo cual se obtiene un correcto destino final, así, un uso beneficioso bajo el aspecto sostenible.

Palabras clave: Suelo dispersivo; Residuos de construcción y demolición; Lima.

\section{Introdução}

O avanço da tecnologia foi acompanhado de um aumento populacional que se estende até os dias atuais. Em razão desse fato, muitas cidades apresentam problemas relacionados à ocupação do espaço urbano, reduzindo a disponibilidade de áreas com boas condições de utilização. O solo, por ser um material importante na definição do comportamento de uma construção, muitas vezes leva a problemas em relação ao ponto de vista da engenharia, que podem se dever à sua composição ou a mudanças nas condições ambientais às quais seja submetido, caracterizando solos em que há a necessidade da utilização de técnicas para torná-lo adequado ao uso.

Argilas dispersivas possuem cátions de sódio dissolvidos na água intersticial, enquanto que as argilas resistentes à dispersão possuem comumente cátions de cálcio e magnésio. As argilas dispersivas erodem facilmente na presença de água, quando a força de repulsão atuante entre as partículas de argila excede a força de atração (Van der Walls), sendo estas partículas progressivamente separadas da massa, ficando em suspensão coloidal.

Segundo Zare-Junaghani (2019), a dispersividade se relaciona à solos argilosos com alta porcentagem de sódio, que são altamente suscetíveis à erosão. Problemas associados aos solos dispersivos têm sido encontrados em várias partes do mundo: Austrália, EUA, Argentina, Brasil, Grécia, Índia, África do Sul, Sérvia e Tailândia, como é descrito por Aitchisonet al. (1963), Sherard et al. (1976), Ferreira (1999), Lafayette et al. (2011), Goodarzi e Salimi, (2015), Hadzi-Niković e Đoković (2019). Portanto, para utilizar esse tipo de solo se faz necessário aplicar técnicas que melhore a característica erodível do solo tornando possível sua aplicação. Sendo assim, pode-se destacar a estabilização e melhoramento de solos como técnica viável.

A estabilização tem o intuito de melhorar as propriedades do solo, como a resistência (Vakili et al., 2020), e ainda a deformabilidade, erodibilidade e permeabilidade. Dessa forma, confere-se maior resistência a cargas, por meio da correção da granulometria ou por adição de materiais ou substâncias que proporcionem maior coesão, proveniente da cimentação ou aglutinação dos grãos do solo (Bordignon et al., 2016). No caso dos solos dispersivos, pode-se destacar a utilização de agregados e de cal, a fim de conferir estabilização mecânica e química, respectivamente.

A técnica a ser utilizada é influenciada por diversos fatores, devendo-se analisar o melhor custo benefício para atender 
às demandas de projeto. Por outro lado, considera-se ainda o fator ambiental, o qual representa atualmente um ponto decisivo nessa escolha. Nesse aspecto, destacam-se os agregados provenientes da reciclagem e reutilização dos resíduos de construção e demolição (RCD), sendo este aplicado para conferir melhoramento de resistência no solo.

Sob o ponto de vista global, a indústria da construção é um dos maiores consumidores de matérias-primas e é responsável pelo descarte de um elevado número de resíduos em todos os seus processos, atingindo percentuais de 30\% e 25\%, respectivamente (Campos \& Conforte, 2020; Altschul, Oliveira \& Nóbrega, 2020; Yazdanbakhsh, 2018). Suas atividades resultam em enormes volumes de RCD, os quais implicam em problemas ambientais, se não destinados corretamente (Bernardo et al., 2016).

Segundo W. Luet al. (2018), a composição dos RCD depende prioritariamente dos materiais utilizados e das tecnologias disponíveis para determinado projeto. Porém, o RCD é composto em sua grande maioria por materiais inertes (argamassa, solo, tijolos e rochas, entre outros) e por outros materiais recicláveis, como plástico, papel, vidro e metais, em percentuais menores. Portanto, o RCD é um material que apresenta grande potencial de reutilização, sob a forma de agregado reciclado, para finalidades diversas, como em camadas de suporte de pavimentos (Nascimento et al., 2020).

Sob o ponto de vista do melhoramento químico do comportamento dispersivo do solo, diversos estudos tem utilizado como base a aplicação da cal hidratada junto ao RCD (Rajesh \& Marimuthu, 2015; Samaniego, 2015; Fuji \& Carvalho, 2014; Figueiredo, 2011). A cal atua por meio de reações químicas de troca catiônica, floculação, reação pozolânica e carbonatação, promovendo melhoria da dispersividade e da resistência mecânica ao longo do tempo (Batalione, 2007).

Assim, buscando aliar a necessidade de alternativas que consomem menos recursos naturais com a possível utilização de RCD, e com a melhoria de um solo de caráter dispersivo, neste trabalho, se objetiva estudar os compósitos obtidos com a mistura de solo, RCD e cal hidratada, a fim de avaliar o comportamento da dispersividade e da resistência à compressão simples com diferentes percentuais de mistura.

\section{Metodologia}

O solo utilizado foi extraído de uma encosta localizada no município da Ilha de Itamaracá, tendo como coordenadas $7^{\circ}$ 46' 9' S e 34 50' 28'" W (Figura 1), a qual possui cerca de 14 metros de altura. A encosta servia como jazida de saibro, a qual foi desativada há cerca de 30 anos, tendo sua estrutura passada por retaludamento e aplicação de sistema de drenagem para conferir maior estabilidade.

O solo foi escolhido devido à forte erosão local e a indícios de dispersividade. O ensaio de Crumb Test foi realizado para definir o ponto em que o solo apresenta maior grau de dispersividade. Foram coletados $200 \mathrm{~kg}$ de solo no estado deformado para realização dos ensaios, estando armazenado em baldes hermeticamente fechados.

O RCD foi coletado em uma usina de beneficiamento, localizada no município de Camaragibe. A usina realiza as etapas de segregação de materiais contaminantes, britagem e peneiramento de resíduos oriundos de construções locais para atingir granulometrias determinadas, e retornar este material para o mercado. Foram coletados $200 \mathrm{~kg}$ de agregados de RCD misto, que possui como componentes materiais cimentícios, cerâmicos e solo de escavação. 
Figura 1. Localização da área de estudo da pesquisa.
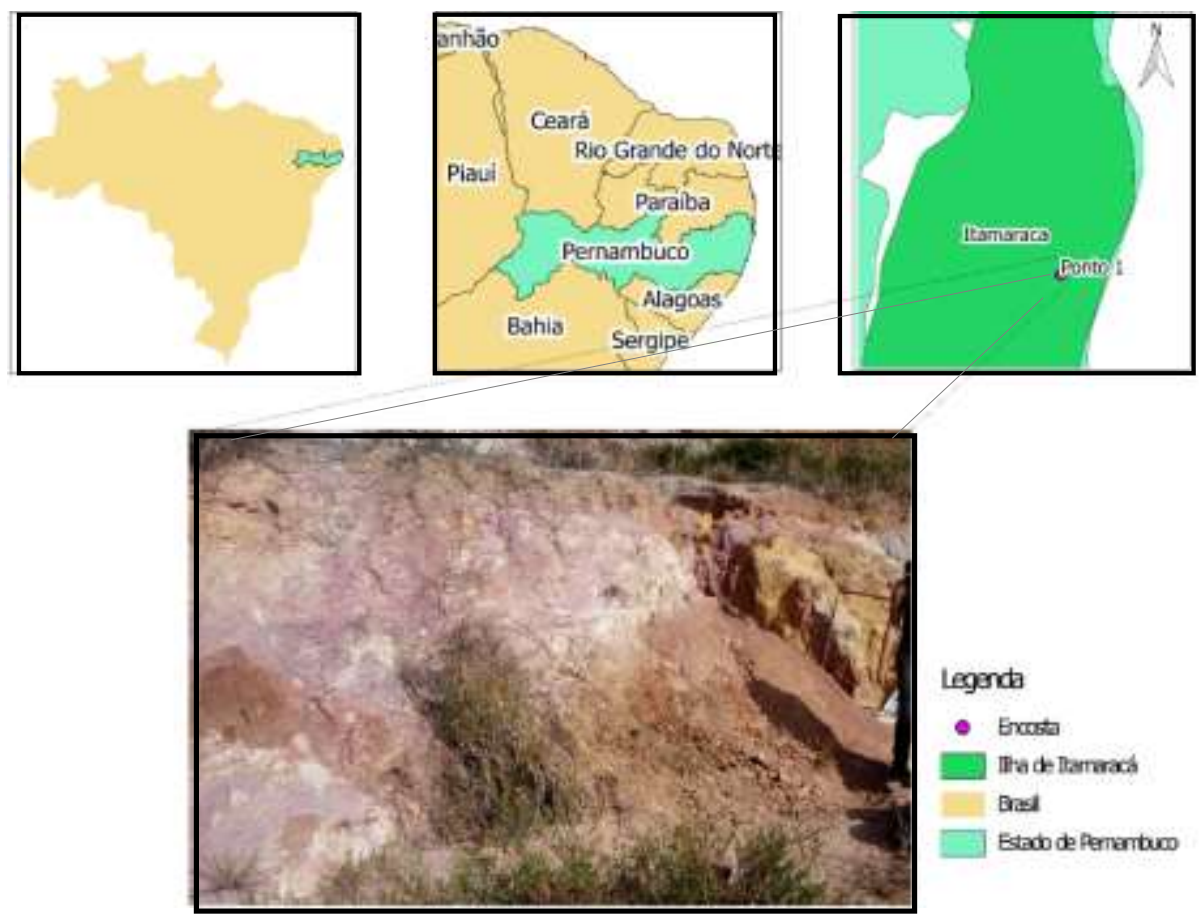

Fonte: Autores.

A cal aplicada nos compósitos se trata de uma CH-I da marca CARBOMIL Química S.A., sendo escolhida em função da qualidade e do grau de pureza, e dos resultados de análise química e física feitas por Ferreira et al. (2017), mostrados na Tabela 1.

O solo e o RCD passaram por um processo de preparação que permitiu uma melhor homogeneização das amostras. Os materiais foram secos ao ar, destorroados e quarteados, e novamente armazenados. Após a realização da granulometria, verificou-se que a distribuição granulométrica dos materiais é semelhante, e por isso, optou-se por utilizar apenas frações de cada um dos deles.

Tabela 1. Resultados das análises químicas e físicas na cal.

\begin{tabular}{l|c|l}
\hline Determinações & $\%$ & 1,31 \\
\hline Umidade & $\%$ & 24,23 \\
\hline Perda ao fogo & $\%$ & 0,22 \\
\hline Óxido de ferro (Fe2O3) & $\%$ & 66,93 \\
\hline Óxido de cálcio total (CaOT) & $\%$ & 58,49 \\
\hline Óxido de cálcio disponível (CaOD) & $\%$ & 4,09 \\
\hline Anidrido Carbônico (CO2) & $\mathrm{g} / \mathrm{ml}$ & 0,45 \\
\hline Massa específica & $\%$ & 0,10 \\
\hline Finura Peneira 30 - 0,600 mm & $\%$ & 0,13 \\
\hline Peneira 200 - 0,075 mm & $\%$ & 87,00 \\
\hline Retenção de água & &
\end{tabular}

Fonte: Ferreira et al.(2017) (adaptado).

Do solo, utilizou-se a fração superior a $300 \mu \mathrm{m}$, e do RCD, a fração inferior a $300 \mu \mathrm{m}$. Os percentuais de composição 
dos materiais foram escolhidos em virtude de resultados positivos de melhoramento de solo obtidos por Leite et al. (2016) e de Martins et al. (2016), sendo apresentados na Tabela 2.

Tabela 2. Percentuais dos materiais utilizados para a produção dos compósitos.

\begin{tabular}{|c|c|}
\hline Nomenclatura & Percentuais utilizados \\
\hline A & $80 \%$ do Solo com partículas $>300 \mu \mathrm{m}+20 \%$ de RCD com partículas $<300 \mu \mathrm{m}$ \\
\hline B & $60 \%$ do Solo com partículas $>300 \mu \mathrm{m}+40 \%$ de RCD com partículas $<300 \mu \mathrm{m}$ \\
\hline $\mathrm{C}$ & $40 \%$ do Solo com partículas $>300 \mu \mathrm{m}+60 \%$ de RCD com partículas $<300 \mu \mathrm{m}$ \\
\hline
\end{tabular}

Fonte: Autores.

Os compósitos preparados foram armazenados em baldes, assim como os materiais coletados, para que fossem realizados os ensaios de caracterização. No entanto, todos os materiais (solo natural, agregados de RCD e compósitos), foram misturados, separadamente, com a cal hidratada, em percentuais de adição, para que se verificasse o seu efeito na dispersividade e na resistência à compressão simples.

Os percentuais de cal hidratada foram definidos após a realização da análise de pH dos materiais sem adição de cal e com adição de 1\%, 3\%, 5\%, 7\% e 9\%, em mistura com água destilada, conforme Eades e Grim (1966). Sendo assim, a partir dos resultados obtidos, os percentuais utilizados para verificação da dispersividade e do comportamento mecânico foram de $3 \%, 5 \%$ e $7 \%$ de adição de cal em peso seco dos materiais.

\subsection{Caracterização Física, Mineralógica e Química}

Os ensaios realizados foram de maneira quantitativa e qualitativa, conforme normas técnicas e autores descritos em cada caracterização. A distribuição granulométrica foi realizada a partir das recomendações das normas D422-63 (ASTM, 2007) e D6913M-17 (ASTM, 2017), sendo a amostra submetida ao peneiramento e sedimentação com aplicação de defloculante (hexametafosfato de sódio) e de dispersor mecânico. As frações foram classificadas pela norma D2487-17 (ASTM, 2017). As massas específicas foram encontradas com o método de ensaio proposto pela norma D854-14 (ASTM, 2014). Já os ensaios para conhecimento dos limites de liquidez e de plasticidade, foram feitos de acordo com a norma D431817e1 (ASTM, 2017).

Executou-se o ensaio de compactação, pois assim é possível conhecer os valores de umidade ótima e densidade seca máxima, parâmetros estes que, segundo Brito e Paranhos (2017), proporcionam um melhor arranjo das partículas, tendo consequência uma melhora no desempenho mecânico. O ensaio foi executado conforme a norma D1557-12e1 (ASTM, 2012) e NBR 7182 (ABNT, 2016), por meio da qual se obtém as curvas de compactação de cada material, utilizando energia Proctor normal.

Analisou-se o RCD e o solo por meio do ensaio de fluorescência de raios-X, a fim de identificar os principais óxidos e elementos químicos que podem interferir nas reações químicas dos materiais com a cal, sendo mostrados os dez mais presentes. As amostras foram secas em estufa a $110^{\circ} \mathrm{C}$ e levadas a levadas a uma mufla, a $1000^{\circ} \mathrm{C}$, por 2 horas, para verificação de perda ao fogo. Outra porção das amostras foi prensada com 30 toneladas e analisadas no espectrômetro Rigaku modelo ZSX Primus II, equipado com tubo de Rh e 7 cristais analisadores.

Quanto à mineralogia, o solo e o RCD passaram por análise da fração maior que 0,075 mm em lupa binocular de marca ZEISS, modelo STEMI 508, com imagem aumentada em 50 vezes, e a fração menor foi submetida a difratometria de raios-X, sob a forma de pó natural não orientado, com difratômetro da marca Shimadzu XRD-6000 com radiação Cu-Ka, 
velocidade de análise de 2,0 graus/min e intervalo $2 \theta$ de 5 a 70 graus.

O estudo do pH foi feito para todos materiais, exceto para o RCD, com adição de $0 \%, 1 \%, 3 \%, 5 \%, 7 \%$ e $9 \%$ de adição de cal em peso seco de amostra, com objetivo de verificar qual o percentual de cal que estabiliza quimicamente o material. Conforme prescreve Eades e Grim (1966), o percentual que estabiliza uma determinada amostra de solo em relação às reações químicas é aquele que confere à mistura um pH de 12,42, entretanto, para Samaniego (2015), existem materiais que não atingem esse valor.

Segundo o autor, estabiliza-se uma amostra, quando, à medida que se adiciona cal, o comportamento do pH é praticamente constante, sendo o percentual estabilizante referente àquele a partir do qual se apresenta esta característica. Os percentuais de 3\%, 5\% e 7\% foram definidos para o estudo das composições com cal, conforme mostra a Tabela 3.

Tabela 3. Nomenclatura dos compósitos adicionados de cal.

\begin{tabular}{|c|c|c|c|c|}
\hline \multirow{2}{*}{$\begin{array}{l}\text { Percentual de } \\
\text { adição de cal }\end{array}$} & \multicolumn{4}{|c|}{ Material } \\
\hline & Solo & A* & B* & C* \\
\hline $0 \%$ & Solo & A & B & $\mathrm{C}$ \\
\hline $3 \%$ & S3 & $\mathrm{A} 3$ & B3 & C3 \\
\hline $5 \%$ & S5 & A5 & B5 & C5 \\
\hline $7 \%$ & S7 & A7 & B7 & C7 \\
\hline
\end{tabular}

Obs.: A* - 80\% Solo+20\% RCD; B* - 60\% Solo+40\% RCD; C* - 40\% Solo+60\% RCD. Fonte: Autores.

\subsection{Caracterização da dispersividade e caracterização mecânica}

Inicialmente, realizou-se o Crumb Test conforme a norma D6572-13e2 (ASTM, 2013) para identificar o grau de dispersividade do solo, ensaio sedimentométrico comparativo (SCS) utilizando as diretrizes da NBR 13602 (ABNT, 1996), e posteriormente o Pinhole Test.

Para o Pinhole Test, as amostras foram ensaiadas de acordo com a norma D4647M-13 (ASTM,2013) e NBR 14114 (ABNT, 1998), sendo preparadas na umidade ótima e densidade seca máxima com 24 horas antes do ensaio, mantidas em câmara úmida. A verificação da dispersividade foi feita tanto para o aumento de carga, quanto para a redução gradativa de carga, a fim de observar o comportamento da vazão, conforme proposto por Lafayette (2006).

Para obter a resistência à compressão simples dos materiais e compósitos, realizou-se o ensaio de acordo com as determinações da norma D2166M-16 (ASTM, 2016) e NBR 12770 (ABNT, 1992). Para tanto, foram moldados três corpos-deprova para cada idade de rompimento, de todos os materiais, individualmente, sendo correspondentes às idades de 7 e 28 dias.

As amostras moldadas foram mantidas em câmara úmida, para que se conservassem as condições de moldagem. Para haver um maior controle das condições de compactação foram estabelecidos intervalos de valores, como critério de aceitação de uso para rompimento (Tabela 4). O rompimento foi feito na mesma prensa de moldagem, com aplicação de carga de 500 Kgf, a uma velocidade de deslocamento de $0,04 \mathrm{~mm} /$ segundo.

Tabela 4. Critérios de aceitação dos corpos-de-prova moldados.

\begin{tabular}{l|l}
\hline Parâmetro & \multicolumn{2}{l}{ Critérios } \\
\hline Grau de compactação (GC) & $100 \% \pm 3 \%$ \\
\hline Teor de umidade (\%) & Valor $\pm 3 \%$ \\
\hline Dimensões (mm) & Diâmetro 50 $\pm 0,5 ;$ Altura 100 \pm 1 \\
\hline
\end{tabular}

Fonte: Adaptado de Macedo (2013). 


\section{Resultados e Discussão}

\subsection{Caracterização Física}

As composições granulométricas dos materiais e compósitos são apresentadas na Tabela 5. O maior percentual é da fração areia, variando de $75 \%$ a $87 \%$, e o menor da fração argila, variando de $1 \%$ a $4 \%$. Observa-se ainda que à medida que se faz a substituição do solo por RCD, o somatório das frações de colóides, argila e silte crescem, sendo compatível com a quantidade de material fino substituído.

A Figura 2 mostra que as curvas granulométricas do solo, RCD e compósitos formatos semelhantes, estando às curvas dos compósitos localizadas entre as dos materiais naturais. As densidades reais dos grãos do solo do RCD e dos compósitos variaram de 2,62 a 2,65. Observa-se ainda que a curva do solo sem defloculante e sem dispersor apresenta modificações, demonstrando mudanças do percentual de dispersão relativo a partículas com diâmetro inferior a 0,005 mm.

Tabela 5. Granulometria das amostras de solo, RCD e compósitos.

\begin{tabular}{l|l|l|l|l|l}
\hline \multirow{2}{*}{ Material } & \multicolumn{1}{l}{ Frações } & \multicolumn{2}{l}{} \\
\cline { 2 - 6 } & Colóides & \multicolumn{1}{l}{ Argila } & \multicolumn{2}{l}{ Silte } & \multicolumn{2}{l}{ Areia } & Pedregulho \\
\hline Solo & $12,70 \%$ & $2,14 \%$ & $6,26 \%$ & $77,70 \%$ & $1,21 \%$ \\
\hline RCD & $5,28 \%$ & $1,18 \%$ & $6,38 \%$ & $86,79 \%$ & $0,38 \%$ \\
\hline A & $7,17 \%$ & $2,64 \%$ & $9,05 \%$ & $81,11 \%$ & $0,03 \%$ \\
\hline B & $7,88 \%$ & $3,33 \%$ & $12,28 \%$ & $76,49 \%$ & $0,01 \%$ \\
\hline C & $9,77 \%$ & $4,38 \%$ & $10,94 \%$ & $74,83 \%$ & $0,07 \%$ \\
\hline
\end{tabular}

Fonte: Autores.

Figura 2. Curva granulométrica do solo, RCD e compósitos.

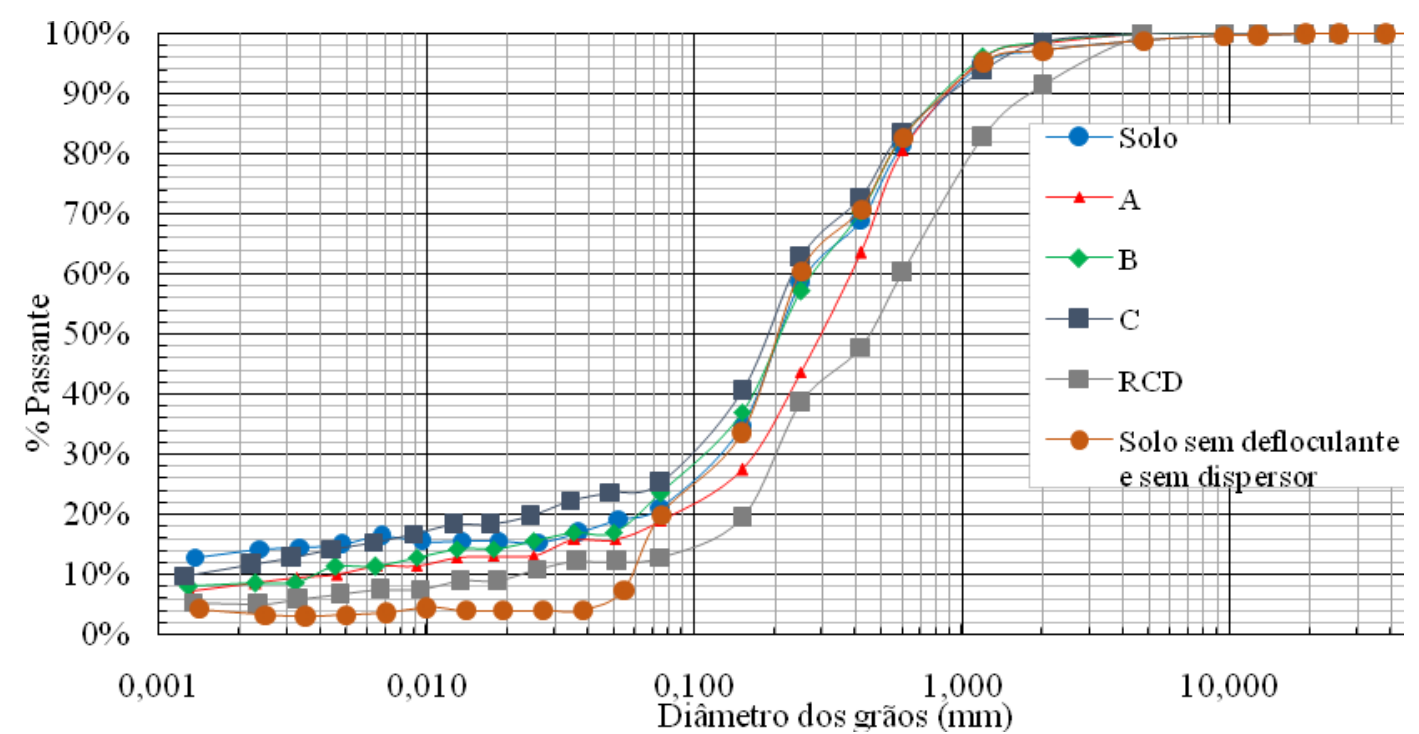

Fonte: Autores.

Nas amostras analisadas não foram observados limites de liquidez e de plasticidade, sendo classificados com comportamentos não plásticos. Isso se explica pela presença de alto teor de areia em suas composições, e em virtude do baixo percentual de elementos coesivos, assim como encontrado por Hammeset al. (2017), Reis e Matos (2017) e Martins et al. (2016). 
Foram determinados os coeficientes de uniformidade $(\mathrm{Cu})$ e de curvatura $(\mathrm{Cc})$ para classificar os materiais pelo Sistema Unificado de Classificação dos Solos (SUCS) (ASTM, 1990). Segundo este sistema de classificação, o solo e os compósitos são considerados como SM, que diz respeito a uma areia siltosa. O RCD, por sua vez é classificado como areia bem graduada, possuindo $\mathrm{Cu}>6$ e $1<\mathrm{Cc}<3$.

Em relação à compactação, observa-se que a curva de compactação dos solos e localiza mais à esquerda e acima da curva do RCD (Figura 3a). O solo apresenta valor de umidade ótima igual a 11,17\% e densidade seca máxima de 1,957 g/ $\mathrm{cm}^{3}$, próximos aos encontrados na pesquisa de Carvalho (2017), referente a uma areia siltosa.

Já o RCD possui umidade ótima igual a 12,69\% e densidade seca máxima de $1,892 \mathrm{~g} / \mathrm{cm}^{3}$, resultado similar ao encontrado por Couto (2017), que utilizou um solo classificado como areia bem graduada. Nos compósitos, a substituição de solo por RCD eleva os valores da umidade ótima e reduz a densidade seca máxima, tendo as curvas picos mais abaixo que as do solo e do RCD (Figura 3b).

Figura 3. Curvas de compactação: do solo e RCD (a); dos compósitos (b).
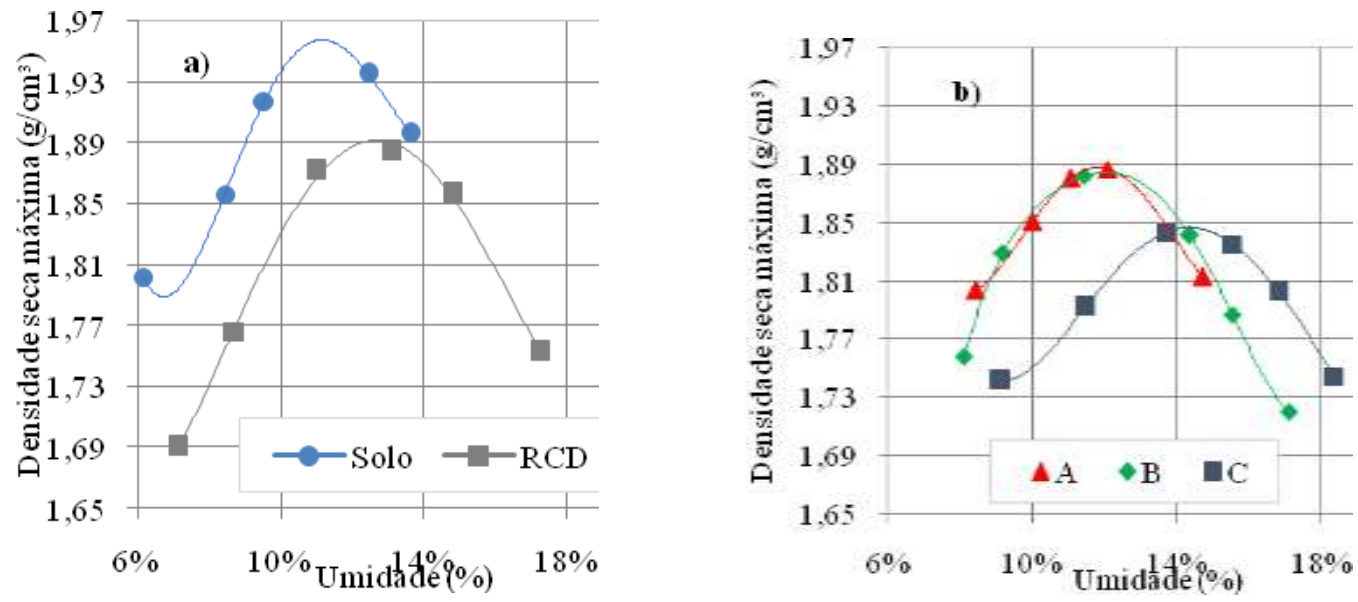

Fonte: Autores.

A medida que se aumenta o teor cal hidratada aplicado ao solo e aos compósitos, a umidade ótima decresce e a densidade seca máxima aumenta (Figura 4). A inserção da cal no solo e nos compósitos resulta em um mistura com menor superfície específica e maior capacidade de absorver água, apresentando uma menor densidade seca máxima para uma mesma energia de compactação apresentada. Comportamento semelhante foi observado por Paiva et al., 2016 e Rocha (2018). 
Figura 4. Curvas de compactação com adição de cal: do solo (a); compósito A (b) compósito B (c); compósitos C (d).
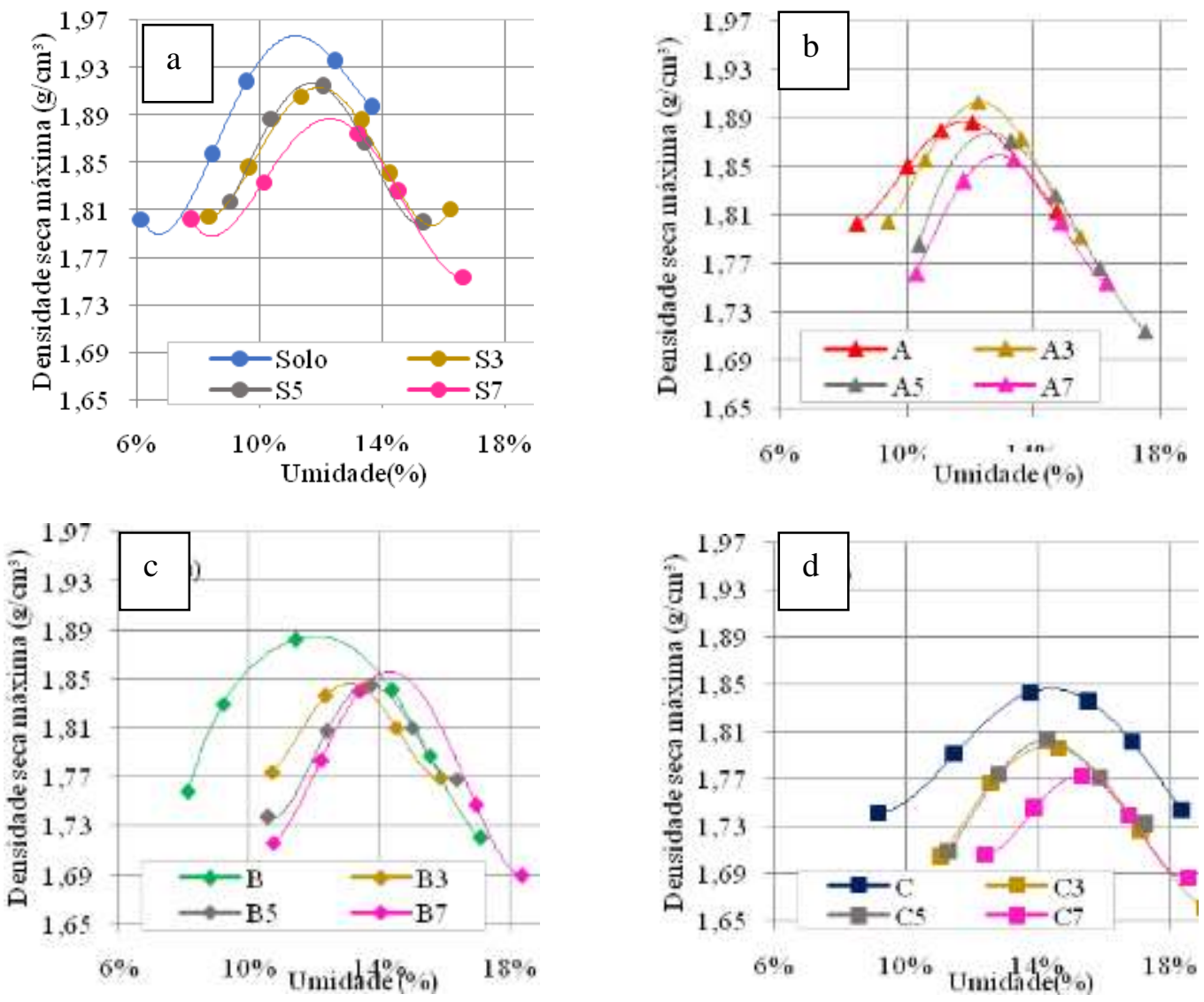

Fonte: Autores

Na Tabela 6 são apresentados os valores de umidade ótima e da densidade seca máxima do solo, do RCD, dos compósitos e dos compósitos com a adição de cal hidratada. Observa-se, com predominância, que à medida que se aumenta a substituição das partículas do solo inferiores a $300 \mu \mathrm{m}$ do solo, por partículas de RCD menores que $300 \mu \mathrm{m}$, formando os compósitos, a umidade ótima cresce e a densidade seca máxima decresce, isto se deve a maior capacidade das partículas do RCD de absorver água. Além disso, o acréscimo da cal hidratada aos compósitos causa aumento da umidade ótima e redução densidade seca máxima devido a menor superfície específica da cal. 
Tabela 6. Umidades ótimas e densidades secas máximas dos materiais.

\begin{tabular}{|c|c|c|}
\hline Material & $\begin{array}{l}\text { Umidade } \\
\text { ótima (\%) }\end{array}$ & $\begin{array}{l}\text { Densidade seca } \\
\text { máxima }\left(\mathrm{g} / \mathrm{cm}^{3}\right)\end{array}$ \\
\hline $\mathrm{RCD}$ & 12,69 & 1,892 \\
\hline Solo & 11,17 & 1,957 \\
\hline $\mathrm{S}+3 \% \mathrm{cal}$ & 12,01 & 1,913 \\
\hline $\mathrm{S}+5 \% \mathrm{cal}$ & 11,68 & 1,917 \\
\hline $\mathrm{S}+7 \% \mathrm{cal}$ & 12,31 & 1,887 \\
\hline $\mathrm{A}$ & 11,84 & 1,887 \\
\hline $\mathrm{A}+3 \% \mathrm{cal}$ & 12,31 & 1,903 \\
\hline $\mathrm{A}+5 \% \mathrm{cal}$ & 12,61 & 1,877 \\
\hline $\mathrm{A}+7 \% \mathrm{cal}$ & 12,93 & 1,859 \\
\hline B & 12,05 & 1,884 \\
\hline $\mathrm{B}+3 \% \mathrm{cal}$ & 13,06 & 1,846 \\
\hline $\mathrm{B}+5 \% \mathrm{cal}$ & 13,73 & 1,845 \\
\hline $\mathrm{B}+7 \% \mathrm{cal}$ & 14,29 & 1,855 \\
\hline $\mathrm{C}$ & 14,36 & 1,846 \\
\hline $\mathrm{C}+3 \% \mathrm{cal}$ & 14,33 & 1,798 \\
\hline $\mathrm{C}+5 \% \mathrm{cal}$ & 14,24 & 1,803 \\
\hline $\mathrm{C}+7 \% \mathrm{cal}$ & 15,28 & 1,773 \\
\hline
\end{tabular}

Fonte: Autores.

\subsection{Caracterização Mineralógica}

A análise dos grãos de solo com lupa binocular indica que há predominância de quartzo hialino, sendo compatível com a granulometria arenosa do material. Verifica-se a presença de argila e ferro aderidos aos grãos e presença de raros minerais acessórios (ilmenita, turmalina e aluminissilicatos).

O RCD também é predominantemente composto por quartzo, estando muitos deles recobertos por argilominerais com impregnação de óxidos e hidróxidos de ferro. Devido a heterogeneidade de sua composição, identifica-se diversos fragmentos de rocha e minerais acessórios como a muscovita, biotita e caulim.

A difratometria de raios $\mathrm{X}$ demonstra que a fração menor que $0,075 \mathrm{~mm}$, nos dois materiais há picos referentes ao quartzo, sendo os mais intensos no solo, enquanto que no RCD há maior intensidade de feldspato. Nos dois há diversos picos de caulinita, estando em maior número no RCD conforme se verifica na Figura 5. 
Figura 5. Difratometria do solo (a) e do RCD (b).
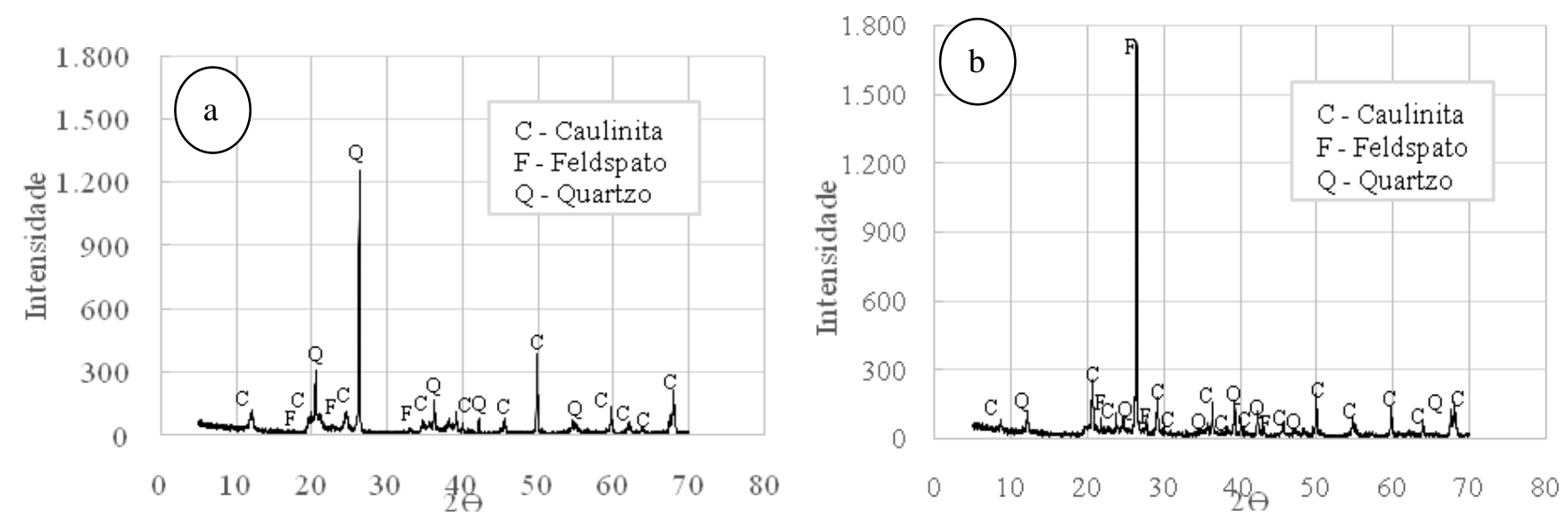

Fonte: Autores.

\subsection{Caracterização Química}

Os resultados de fluorescência de raios-X mostram que o solo é predominantemente constituído por sílica $(56,63 \%)$, óxido de alumínio $(27,48 \%)$ e óxido de ferro (4,94\%) e o RCD também tem predomínio desses óxidos (Tabela 7). Entretanto, deve-se destacar que no resíduo há maior percentual de óxido de cálcio, que é um componente da cal, demonstrando que nesse material existe uma predominância de componentes que agem no ganho de resistência.

Outro fator a ser destacado é a perda ao fogo, pois esse fator indica que materiais que possuem maior perda ao fogo, contém mais argilominerais. O resíduo mostra maior perda ao fogo que o solo, demonstrando que possui mais argilominerais em sua composição. Esse fator é benéfico, tendo em vista que a cal reage quimicamente com esses argilominerais conferindo ganho de resistência ao longo do tempo.

Tabela 7. Percentuais de óxidos presentes no solo e no RCD.

\begin{tabular}{|c|c|c|c|c|c|c|c|c|c|c|c|}
\hline Material & Óxidos & & & & & & & & & & \\
\hline \multirow{2}{*}{ Solo } & $\mathrm{Na}_{2} \mathrm{O}$ & MgO & $\mathrm{Al}_{2} \mathrm{O}_{3}$ & $\mathrm{SiO}_{2}$ & $\mathrm{P}_{2} \mathrm{O}_{5}$ & $\mathrm{~K}_{2} \mathrm{O}$ & $\mathrm{CaO}$ & $\mathrm{TiO}_{2}$ & $\mathrm{Fe}_{2} \mathrm{O}_{3 \mathrm{t}}$ & $\mathrm{SO}_{3}$ & P.F \\
\hline & 0,03 & 0,09 & 27,48 & 56,63 & 0,04 & 0,22 & 0,07 & 1,38 & 4,94 & 0,08 & 8,68 \\
\hline \multirow{2}{*}{ Resíduo } & $\mathrm{Na}_{2} \mathrm{O}$ & MgO & $\mathrm{Al}_{2} \mathrm{O}_{3}$ & $\mathrm{SiO}_{2}$ & $\mathrm{P}_{2} \mathrm{O}_{5}$ & $\mathrm{~K}_{2} \mathrm{O}$ & $\mathrm{CaO}$ & $\mathrm{TiO}_{2}$ & $\mathrm{Fe}_{2} \mathrm{O}_{3 \mathrm{t}}$ & $\mathrm{SO}_{3}$ & P.F \\
\hline & 0,31 & 1,02 & 22,02 & 44,01 & 0,31 & 1,57 & 10,21 & 0,85 & 4,28 & 2,04 & 13,08 \\
\hline
\end{tabular}

A Figura 6 apresenta a variação o pH com o acréscimo de cal no solo, no RCD e nos compósitos. $\mathrm{O}$ pH do solo $(7,2)$, do RCD $(8,5)$ e dos compósitos é alcalino. Nenhum dos materiais atingiu o valor de 12,42 (recomendado por Eades e Grim, (1966) para a estabilização química), no entanto, o comportamento constante de $\mathrm{pH}$ foi observado em todas as amostras a partir de 5\% de adição de cal. O solo apresentou o maior valor de $\mathrm{pH}, 12,14$, enquanto que nos compósitos os valores foram inferiores ao do solo, sendo o pH tanto menor quanto maior a substituição, com valores de 10,68; 10,56; e 10,09 para os compósitos A, B e C, respectivamente. 
Figura 6. Valores de $\mathrm{pH}$ relacionados aos percentuais de cal aplicados no solo e misturas com RCD.

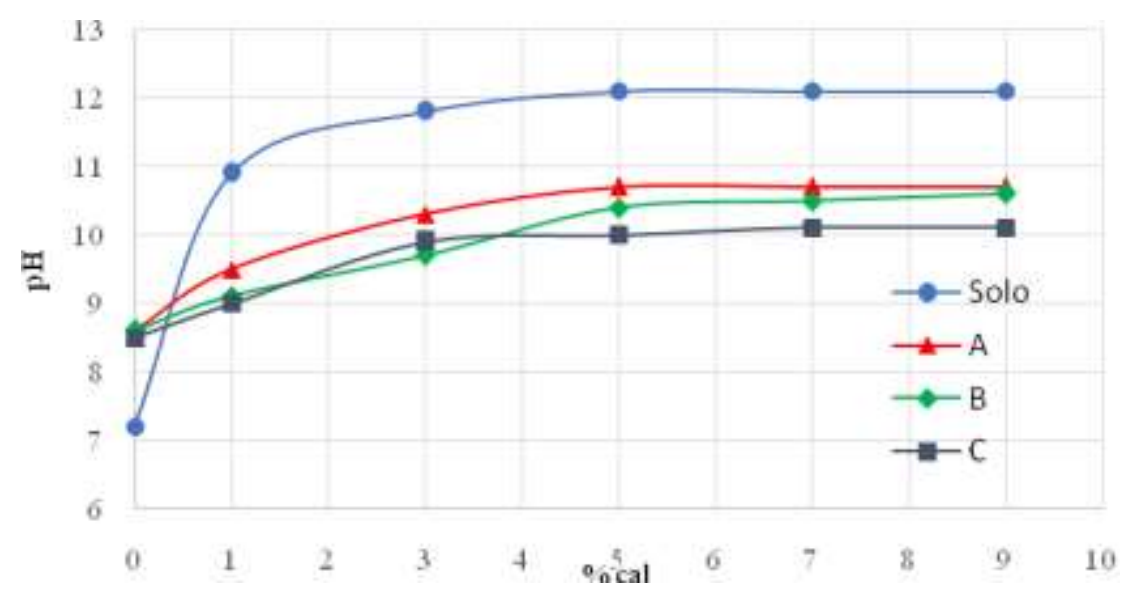

Fonte: Autores.

\subsection{Caracterização da dispersividade e caracterização mecânica}

A visita de campo e as observações realizadas indicam um forte processo de erosão com indicativo da presença de argilas dispersivas (Figura 7). A análise inicial dos resultados obtidos por meio Crumb Test, demonstra a formação de colóides em suspensão e o torrão inserido se espalhou no fundo do béquer, deixando a água com aparência turva, que indica a presença de argila dispersiva, com grau de dispersividade 3 (D6572-13e2 ASTM, 2013), caracterizando o solo como moderadamente dispersivo.

Figura 7. Processo avançado de erosão.

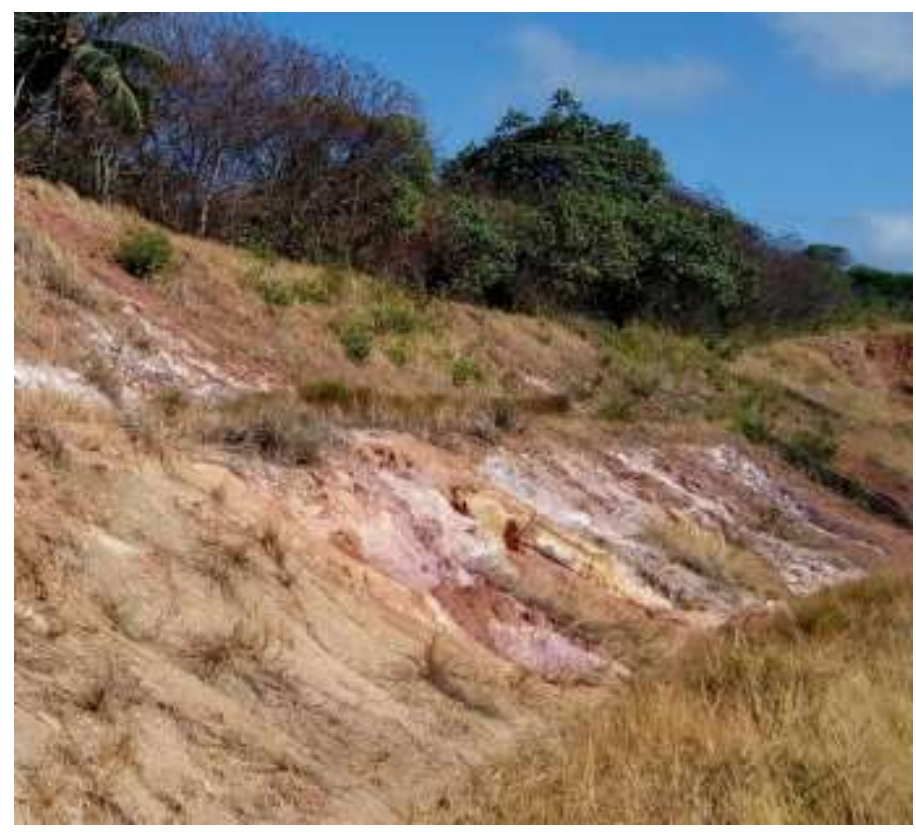

Fonte: Autores.

A porcentagem das partículas do solo com dimensão inferior a $0,005 \mathrm{~mm}$, obtida no ensaio com defloculante é $14,84 \%$, e no solo sem defloculante é $3,18 \%$. Assim a razão em percentual que indica a Porcentagem de Dispersão (PD) é de $21,43 \%$, classifica o solo como ligeiramente dispersivo (150\% < PD < 30\%), conforme Rajesh e Marimuthu (2015) e solo dispersivo conforme proposto por MSL 12 (CESP, 1983). 
A Tabela 8 mostra os teores de cálcio, magnésio, sódio e potássio dissolvidos em água, e com eles foram calculados os parâmetros de análise da dispersividade. Os resultados obtidos demonstram que no solo, o percentual de sódio na água livre é alto, em relação aos demais sais presentes, com valor de $85,47 \%$. Com base nesta informação, junto ao total de sais dissolvidos (TSD), e utilizando a metodologia proposta por Sherard et al. (1976), verificou-se que o solo se enquadra na classificação da zona dispersiva), corroborando os resultados verificados nos ensaios de Crumb Test, Ensaio SCS.

Tabela 8. Teores de sais, TSD, PS e RAS.

\begin{tabular}{|c|c|c|c|c|c|c|}
\hline \multicolumn{4}{|c|}{$\begin{array}{c}\text { Teores de sais na água } \\
\text { intersticial (meq/l) }\end{array}$} & \multicolumn{2}{|r|}{ PS (\%) } & $\begin{array}{c}\text { Ras } \\
\mathrm{Na}^{*}\end{array}$ \\
\hline $\mathrm{Na}^{+}$ & $\mathrm{K}^{+}$ & $\mathrm{Ca}^{2+}$ & $\mathrm{Mg}^{2+}$ & $T S D=C a^{2+}+M g^{3+}+N a^{+}+K^{+}$ & $P S(\%)=\left(\frac{N a^{+}}{T S D}\right) \times 100$ & $R A S=\frac{N a^{*}}{\sqrt{\left(\frac{6 s^{32}+3 g^{g^{2}}}{z}\right)}}$ \\
\hline 0,06 & 0,19 & 1,53 & 0,01 & 1,79 & 85,47 & 4,37 \\
\hline
\end{tabular}

Fonte: Autores.

Na Figura 8 são mostrados os valores de vazão média do solo, RCD e compósitos sem a adição cal, ensaiados em cada carga hidráulica, tanto na fase de acréscimo de carga quanto na de alívio (descarga). No solo, verifica-se que para a carga hidráulica inicial de 50,8 mm há uma vazão média de 1,57 ml/s, sendo o efluente escuro nos 5 minutos iniciais. Devido a esse fato, cada carga foi mantida por 10 minutos, segundo recomenda a NBR 14114 (ABNT, 1998), e foi visto que a água percolada permaneceu com aspecto turvo. Finalizado o ensaio, observa-se que o diâmetro do furo aumentou cerca de duas vezes em relação ao furo inicial, fato mostrado pela diferença das retas de carga e descarga no gráfico da Figura 8. O solo é classificado como D2, correspondente a um solo dispersivo.

Figura 8. Resultado do ensaio de Pinhole do solo, RCD e compósitos.

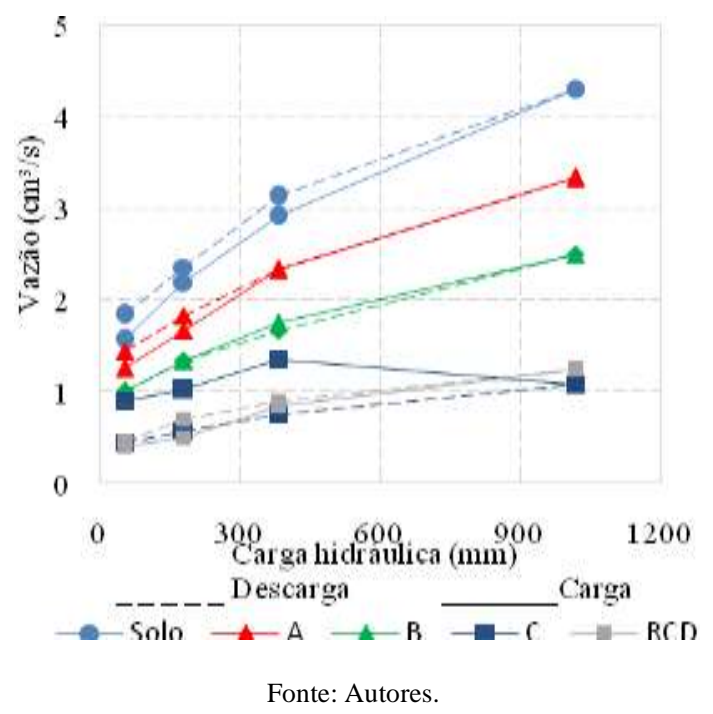

No RCD e nos compósitos A, B e C se verifica aspecto de água limpa ao longo do ensaio, sendo mantidos os diâmetros dos furos. A substituição da fração fina do solo por RCD foi eficaz para todos os percentuais analisados, tendo em vista que todos os compósitos não demonstraram dispersividade, tendo sua classificação como ND1. Ressalta-se que no compósito C, que possui mais RCD em sua composição, houve carreamento de partículas que ficaram retidas no cascalho e redução do diâmetro da trajetória do fluxo, refletindo no comportamento da vazão na fase de alívio de carga.

O aumento do percentual de RCD provoca redução de vazão, estando as retas representativas das vazões localizadas 
entre a do solo e do RCD. O compósito A, seguido do B e C, respectivamente demonstraram diminuição da vazão na carga hidráulica máxima, e assim, pode-se inferir que quanto maior a substituição da fração de solo com dimensões menores que 300 $\mu \mathrm{m}$, por partículas menores que $300 \mu \mathrm{m}$ do RCD, menor será a vazão, entretanto há maior possibilidade de erodibilidade, a qual age por fenômeno mecânico.

As curvas de tempo versus carga hidráulica do solo e dos compósitos adicionados de cal são mostradas na Figura 9 e 10. A adição de cal reduz as vazões a valores inferiores à do solo, e superiores ou iguais à do RCD. Não houve mudança de coloração da água, sendo, portanto, classificados como ND1, que são solos não dispersivos, demonstrando que a adição de cal eliminou o comportamento dispersivo proveniente do solo, tanto nas misturas solo-cal quanto nos compósitos. Similar resultado foi encontrado por Samaniego (2015).

No solo (Figura 9a), a adição de cal provoca mudança de vazão entre a fase de carregamento e de alívio de carga, em relação ao solo natural. No entanto, observa-se que não houve aumento do diâmetro do furo e nem deslocamento de partículas, tendo a cal contribuído para a redução da erodibilidade do solo.

Em relação aos compósitos, apenas para o compósito A, com adição de 3\%, 5\% e 7\% de cal, houve diferenciação em relação ao diâmetro do furo, fato que é corroborada pela Figura 9b, no qual se verifica que as vazões de carga são superiores à de descarga. Dessa forma, os compósitos A+3\% de cal, A+5\% de cal e A+7\% de cal, apesar de serem não dispersivos, apresentam mau comportamento frente à erosão, demonstrando redução do fluxo e deposição de partículas no cascalho do equipamento.

Figura 9. Resultados do Pinhole Test do solo e compósitos com cal: solo (a), compósito A (b).
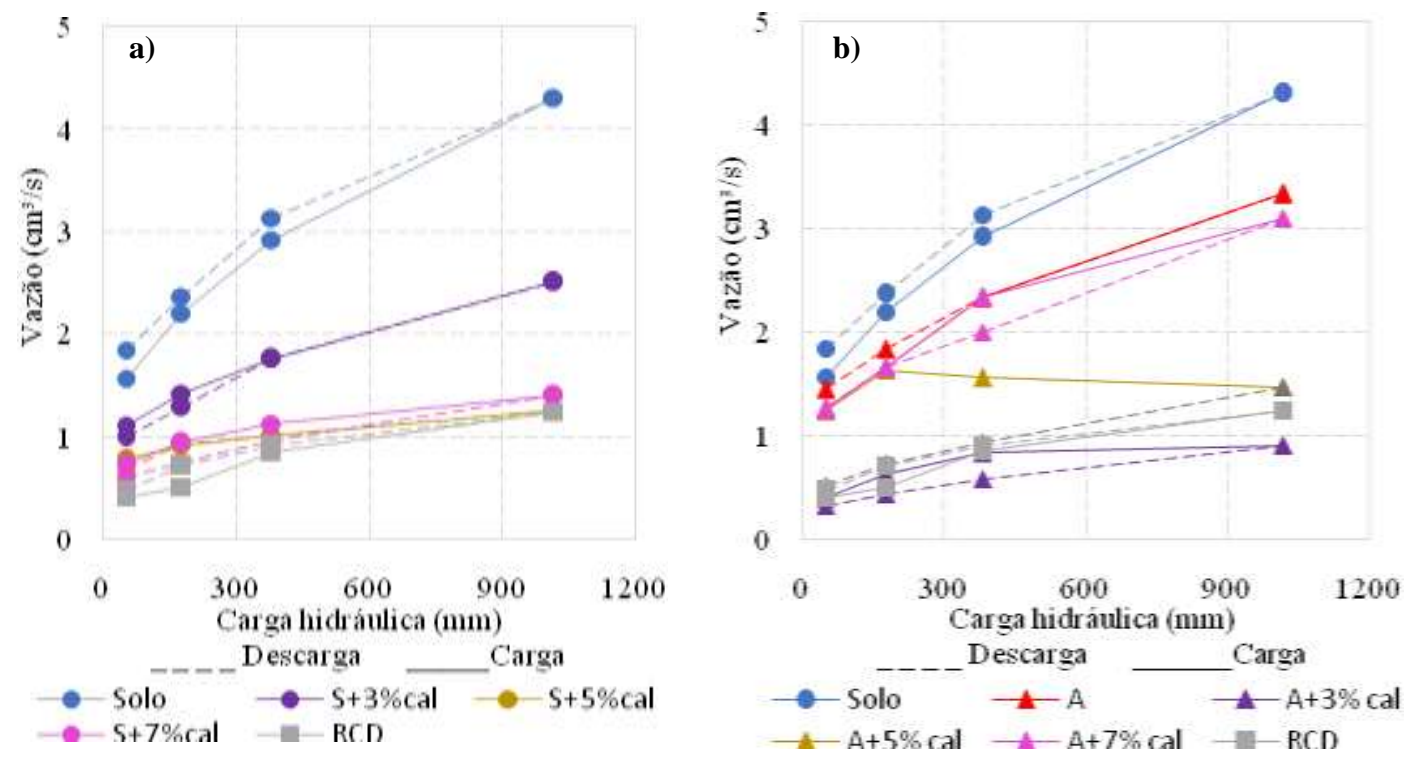

Fonte: Autores.

Os compósitos B e C (Figuras 10a e 10b) apresentaram bom comportamento em relação à dispersividade e à erodibilidade, em todos os percentuais de adição de cal. Dessa forma, evidencia-se que para estes compósitos quaisquer dos percentuais de cal testados poderiam ser utilizados, pois melhoram as duas características indesejadas do solo natural. Considerando o custo, o de menor percentual de cal é o indicado. 
Figura 10. Resultados do Pinhole Test dos compósitos com cal: compósito B (a), compósito C (b).
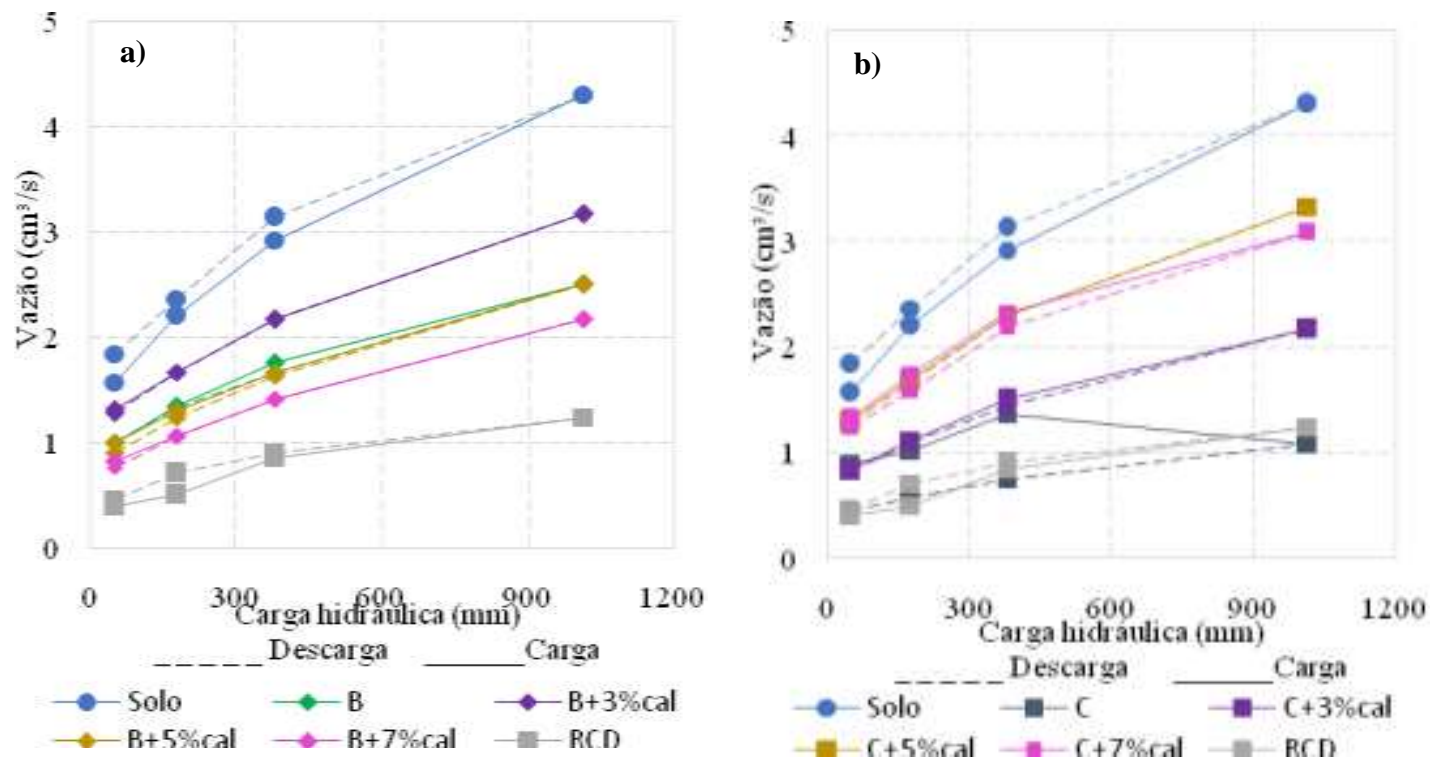

Fonte: Autores.

Os resultados de resistência à compressão simples dos materiais estão apresentados na Tabela 9. O tipo de ruptura frágil, com ângulo de ruptura da ordem de $60^{\circ}$, indica que os materiais romperam sem grandes evidências de deformação. A resistência à compressão simples do solo $(254 \mathrm{kPa})$ é superior a do $\mathrm{RCD}(133 \mathrm{kPa})$ e a dos compósitos $\mathrm{A}(37 \mathrm{kPa}), \mathrm{B}(77 \mathrm{kPa})$ e C (129 kPa), considerando que todos os ensaios foram realizados na condição a de umidade ótima e densidade seca máxima de cada material ou mistura. A substituição, apenas das partículas do solo inferiores $300 \mu \mathrm{m}$ por partículas do RCD menores que $300 \mu \mathrm{m}$, não impacta em acréscimo de resistência.

Em análise comparativa, verifica-se que, como esperado, aos 28 dias todas as resistências aumentaram em relação aos valores de 7 dias de cura úmida. Entretanto, os compósitos sem cal tiveram aumentos percentuais superiores às demais misturas, atingindo ganhos de resistência que variam entre $60 \%$ e $130 \%$, com o tempo. O solo, com a adição de cal, apresentou valores inferiores de resistência quando se compara ao seu estado natural. Entende-se, com base em Azevêdo (2010) que as reações entre os argilominerais do solo, a cal e a água não ocorreram totalmente, tendo em vista que a cimentação proveniente da reação da cal ocorre de forma lenta. 
Tabela 9. Valores de resistência à compressão simples das amostras ensaiadas aos 7 e 28 dias de cura.

\begin{tabular}{c|c|c}
\hline \multirow{2}{*}{ Material } & \multicolumn{2}{|c}{ Tensão de ruptura média (kPa) } \\
\cline { 2 - 3 } & 7 Dias & 28 Dias \\
\hline RCD & 133 & 194 \\
\hline Solo & 254 & 289 \\
\hline S+3\% cal & 116 & 179 \\
\hline S+5\% cal & 194 & 302 \\
\hline S+7\% cal & 206 & 218 \\
\hline A & 37 & 85 \\
\hline$A+3 \%$ cal & 178 & 206 \\
\hline$A+5 \%$ cal & 241 & 248 \\
\hline$A+7 \%$ cal & 272 & 396 \\
\hline$B$ & 77 & 180 \\
\hline$B+3 \%$ cal & 301 & 340 \\
\hline $\mathrm{B}+5 \%$ cal & 507 & 570 \\
\hline $\mathrm{B}+7 \%$ cal & 687 & 787 \\
\hline$C$ & 129 & 208 \\
\hline $\mathrm{C}+3 \%$ cal & 324 & 409 \\
\hline $\mathrm{C}+5 \%$ cal & 613 & 853 \\
\hline $\mathrm{C}+7 \%$ cal & 877 & 1150 \\
\hline
\end{tabular}

Fonte: Autores.

Nos compósitos que possuem cal há uma variação de valores de resistência que aos 7 dias compreende o intervalo de $116 \mathrm{kPa}$ até $877 \mathrm{kPa}$, que correspondem ao compósito $\mathrm{S}+3 \%$ de cal e compósito C+7\% de cal, respectivamente. Aos 28 dias esse intervalo variou entre $179 \mathrm{kPa}$ e $1150 \mathrm{kPa}$, ambos para os mesmos materiais citados. Comportamento semelhante foi encontrado por Rajesh e Marimuthu (2015).

Para comparar os efeitos da substituição da fração de solo por RCD em diferentes proporções, ou seja, o comportamento dos compósitos sem adição de cal, e com os distintos percentuais de cal, mostra-se na Figura 11 os valores de resistência à compressão simples, em kPa, em função da quantidade de cal presente na mistura aos 7 dias de cura úmida.

Figura 11. Resultados de resistência à compressão dos materiais aos 7 dias de cura úmida.

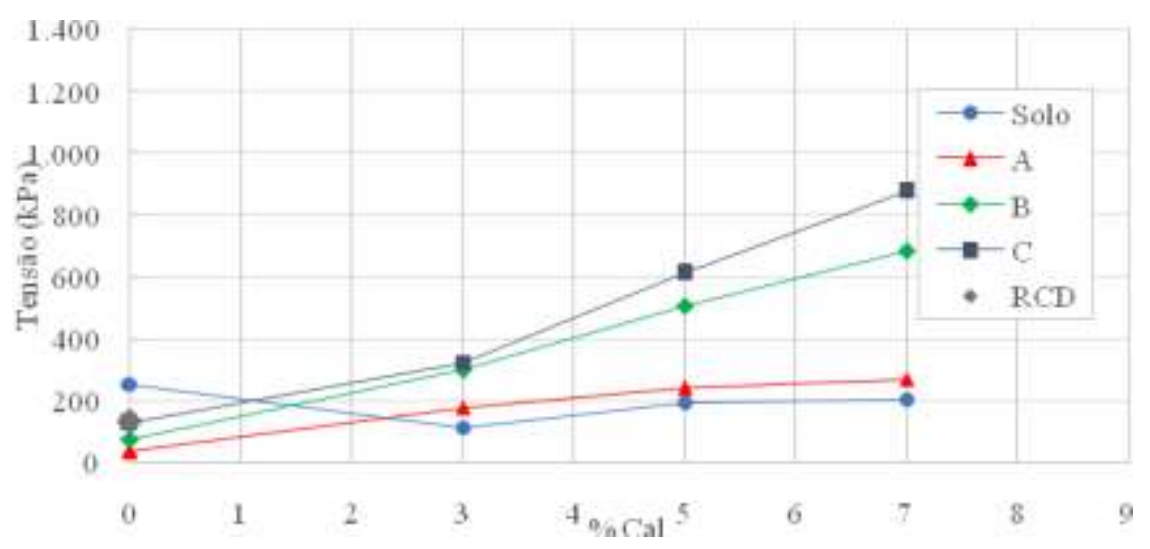

Fonte: Autores.

Na primeira idade de ruptura, quanto à substituição de solo por RCD, verifica-se que não houve ganhos significativos, tendo o solo sem adição valor de resistência superior aos compósitos A, B e C, e, este último, valor próximo ao do RCD. A adição de cal, entretanto modificou esse comportamento. Exceto para o solo, a adição de cal elevou os valores de resistência em relação aos materiais sem adição. 
Nota-se que, em relação ao solo sem adição, os compósitos $\mathrm{B}$ e C a partir de 3\% de cal possuem resistência superior à do solo, sendo a maior delas correspondente ao acréscimo de 7\% de cal com o maior percentual de RCD (compósito C7). Quanto ao compósito A, percebe-se um aumento de resistência com a adição de cal.

Em relação aos rompimentos de 28 dias (Figura 12), no solo, nota-se que o aumento em relação aos 7 dias foi de $14 \%$. A adição de cal nesta idade, entretanto, refletiu ganhos de resistência com 7\% de cal, quando se compara ao solo sem adição, demonstrando os efeitos cimentantes da cal ao longo do tempo.

Figura 12. Resultados de resistência à compressão dos materiais aos 28 dias de cura úmida.

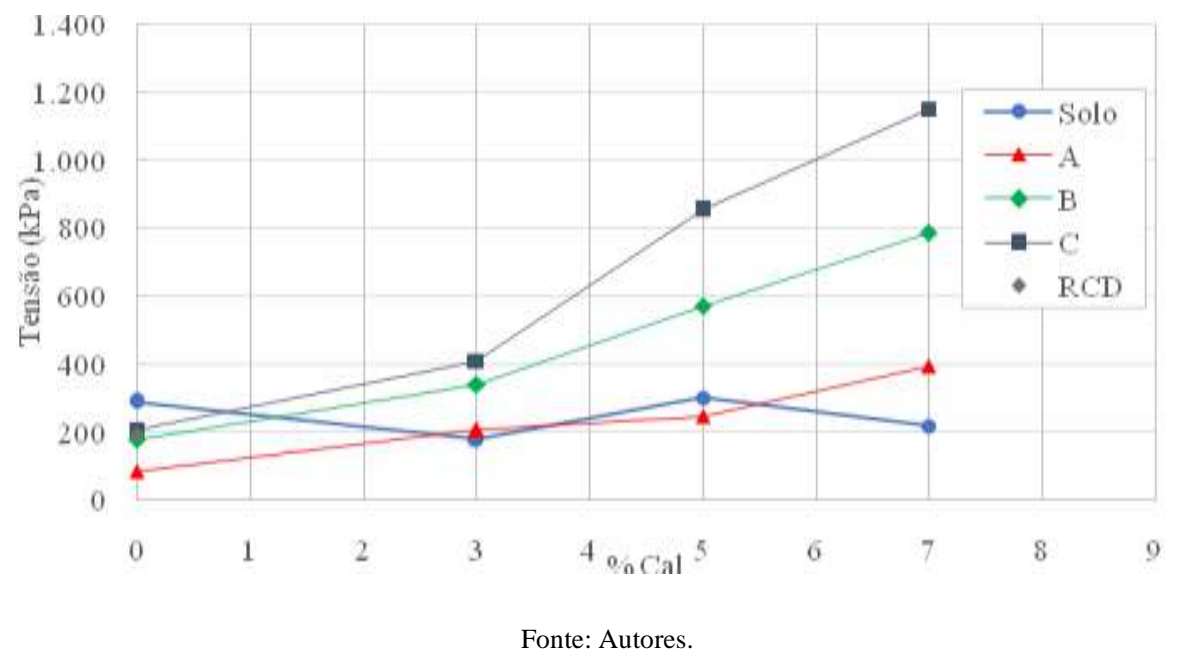

Quanto aos compósitos A, B e C, observa-se que, sem a cal, as resistências foram inferiores à do solo, assim como nos 7 dias. Sendo possível constatar, que sem a adição de cal, a substituição da fração fina de solo pela de RCD não impactou em ganhos, pois interfere diretamente na resistência mecânica, fato que era esperado, pois, retirou-se a fração coesiva do solo, estando o compósito mais frágil.

Com a cal os resultados são positivos. Quanto ao comportamento geral, apenas o compósito A3 e A5 representaram valores inferiores ao do solo sem adição, podendo isto se dever a heterogeneidade do RCD, cuja composição pode apresentar materiais que reduzem a resistência, a exemplo do gesso, os quais não foram identificados por composição gravimétrica, devido ao material ter sido adquirido beneficiado. Os demais foram superiores ao do solo, sendo os maiores valores de resistência do compósito C com quaisquer percentuais de cal, atingindo ganhos de até 300\%, aproximadamente.

Tal comportamento, nos compósitos, se deve às reações da cal com os argilominerais presentes na parcela de RCD utilizada, tendo em vista que o resíduo é composto por diversos materiais, como argila, areia, restos de argamassa, cerâmica, dentre outros, que podem reagir com a cal. Essas reações, portanto, provocam ao longo do tempo aumento de resistência por reação pozolânica e por carbonatação (Batalione, 2007). Assim, os compósitos de $40 \%$ e $60 \%$ de RCD, por possuir mais resíduos em sua composição, em relação ao solo natural e ao compósito A, refletem maiores ganhos de resistência ao longo do tempo, com maiores percentuais de cal adicionados.

\section{Considerações Finais}

Diante dos resultados obtidos, é possível afirmar que a utilização de compósitos obtidos por substituição da fração argilosa de solo por RCD, possibilita a retirada do caráter dispersivo da mistura, mostrando que é viável a melhoria da dispersividade por este método, sendo o melhor resultado encontrado para o compósito com 40\% de RCD. 
Porém é preciso utilizar dosagens, tais quais se minimize a ocorrência de erodibilidade, a fim de evitar carreamento de partículas por erosão mecânica, como a ocorrida no compósito C, o qual possui $60 \%$ de RCD em sua composição, ou aplicar adições que modifiquem este comportamento, como a cal.

Verifica-se que a cal, proporciona a eliminação da dispersividade no solo, por adição em peso seco de solo e acarreta na redução da erodibilidade do solo. Nos compósitos, com exceção dos compósitos A com cal, também se verifica eliminação da dispersividade e da erodibilidade, tendo os compósitos B e C bom comportamento do material frente à erosão com quaisquer percentuais de cal adicionada.

Por outro lado, tanto a substituição da fração menor que $300 \mu \mathrm{m}$ do solo pela fração equivalente de RCD, quanto a adição da cal hidratada no solo, não conduz a resultados significativos de resistência à compressão simples. Entretanto, a adição de cal nos compósitos com maiores percentuais de RCD (40\% e 60\%) elevou significativamente a resistência à compressão analisada, atingindo ganhos superiores a 172\% e, aproximadamente 300\% em relação ao solo, respectivamente.

Sendo assim, é possível afirmar que a utilização de compósitos de solo, resíduos de construção e demolição e cal hidratada possui viabilidade, tanto para a eliminar a dispersividade, sem comprometer a erodibilidade, quanto para melhoria de resistência à compressão simples, sendo o $\mathrm{C} 7(40 \%$ Solo+60\% RCD+7\% Cal) o compósito que melhor alia a redução de dispersividade, erodibilidade e aumento da resistência à compressão.

Dessa forma, os compósitos devem ser utilizados com dosagens de solo, RCD e cal, conjuntamente, e escolhidos traços que proporcionem um melhor equilíbrio das propriedades desejadas. Assim, é possível dar uma destinação correta e novo uso para o RCD, sem comprometer as características dos materiais.

Assim, é importante analisar os compósitos em teores intermediários, que possam ser verificados os acréscimos de resistência dos materiais e identificar qual o teor ideal de agregados reciclados, conforme as normas estabelecidas.

\section{Referências}

Aitchison, G. D., Ingles, O. G., \& Wood, C. C. (1963). Post-Constructin Deflocculation as a Contributory in the Failure of Earth Dams 4 th Australian-New Zealand Conference on SMFE, 275-279.

American Society For Testing And Materials (ASTM). (1990). Annual book of ASTM standards. Section 4: Construction, v.04: Soil and rock, dimension stone, geosynthetics. Philadelphia.

American Society For Testing And Materials (ASTM). D6572-13e2. (2013). Standard Test Methods for Determining Dispersive Characteristics of Clayey Soils by the Crumb Test. West Conshohocken, PA.

American Society For Testing And Materials (ASTM). D854-14. (2014). Standard Test Methods for Specific Gravity of Soil Solids by Water Pycnometer. West Conshohocken, PA.

American Society For Testing And Materials (ASTM). D422-63. (2007) e2. Standard Test Method for Particle-Size Analysis of Soils (Withdrawn 2016). West Conshohocken, PA.

American Society For Testing And Materials (ASTM). D6913M-17. (2017). Standard Test Methods for Particle-Size Distribution (Gradation) of Soils Using Sieve Analysis. West Conshohocken, PA.

American Society For Testing And Materials (ASTM). D4318-17e1. (2017). Standard Test Methods for Liquid Limit, Plastic Limit, and Plasticity Index of Soils. West Conshohocken, PA.

American Society For Testing And Materials (ASTM). D4647M-13. (2013). Standard Test Methods for Identification and Classification of Dispersive Clay Soils by the Pinhole Test. West Conshohocken, PA.

American Society For Testing And Materials (ASTM). D1557-12e1. (2012). Standard Test Methods for Laboratory Compaction Characteristics of Soil Using Modified Effort. West Conshohocken, PA.

American Society For Testing And Materials (ASTM). D2166M-16. (2016). Standard Test Method for Unconfined Compressive Strength of Cohesive Soil. West Conshohocken, PA.

American Society For Testing And Materials (ASTM). D2487-17. (2017). Standard Practice for Classification of Soils for Engineering Purposes (Unified Soil Classification System). West Conshohocken, PA.

Associação Brasileira de Normas Técnicas (ABNT). (2016). NBR 7182. Solo - Ensaio de compactação. Rio de Janeiro. 
Associação Brasileira de Normas Técnicas (ABNT). (1992). NBR 12770. Solo coesivo - Determinação da resistência à compressão não confinada. Rio de Janeiro.

Associação Brasileira de Normas Técnicas (ABNT). (1996). NBR13602. Solo - Avaliação da dispersibilidade de solos argilosos pelo ensaio sedimentométrico comparativo - Ensaio de dispersão SCS. Rio de Janeiro. 5 p.

Associação Brasileira de Normas Técnicas (ABNT). (1998). NBR 14114. (1998). Solo - Solos argilosos dispersivos - Identificação e classificação por meio do ensaio do furo de agulha (pinhole test). Rio de Janeiro, 1998. 8p.

Altschul, J. S., Oliveira, I. P. V., \& Nóbrega, M. J. R. (2020). Resíduo da construção e demolição-tecnologias e problemas: um estudo de caso. Revista Tecnológica da Universidade Santa Úrsula, (1), 13-31.

Azevêdo, A. L. (2010). Estabilização de solos com adição de cal. Um estudo a respeito da reversibilidade das reaçães que acontecem no solo após a adição de cal. 114 f. Dissertação (Mestrado) - Universidade Federal de Ouro Preto, Ouro Preto.

Batalione, G. (2007). Estabilização de solos tropicais com a utilização de rejeitos finos de pedreira de uma rocha granítica. 190 f. Dissertação (Mestrado) Universidade de Brasília, Brasília.

Bernardo, M., Gomes, M. C. \& Brito, J. de (2016). Demolition waste generation for development of a regional management chain model. Waste management, Lisboa, p. 1-14.

Bordignon, V. R., Puppi, R. F. K., Izzo, R. L. S. \& Johann, A. D. R. (2016). Estudo da viabilidade tecnológica do emprego de cal em um solo da formação guabirotuba para fins de pavimentação. In: Congresso Brasileiro de Mecânica dos Solos e Engenharia Geotécnica, 18. Belo Horizonte. Anais... Belo Horizonte, 2016, p. 1-9.

Brito, L. C.\& Paranhos, H. S. Estabilização de solos. (2017). Revista Científica Multidisciplinar Núcleo do Conhecimento, Salvador, 1(6), 425 - 438.

Campos, C. S., \& Conforte, M. E. (2020). Análise da gestão de resíduos em relação à Política Nacional de Resíduos Sólidos no Rio de Janeiro. Boletim do Gerenciamento, 15(15), 1-12.

Carvalho, M. V. (2017). Influência do reuso de amostras no ensaio de compactação de dois latossolos de Minas Gerais. 2017. 38 f. Trabalho (conclusão de curso) - Universidade Federal de Ouro Preto, Ouro Preto.

Companhia Hidrelétrica de São Paulo (CESP). (1983). Métodos de ensaios de erodibilidade em solos: pinhole test, porcentagem de dispersão e ensaios de turbidez. Illha Solteira, SP: Laboratório Central de Engenharia Civil da CESP, 34 p.

Couto, L. A. F. A. H. R. (2017). Caracterização geotécnica de areia reciclada produzida a partir de resíduos de construção e demolição do município de Natal/RN. 2017. 19 f. Trabalho (Conclusão de Curso) - Universidade Federal do Rio Grande do Norte, Natal.

Eades, J. L. \& Grim, R. E. (1966). A quick test to determine lime requirements for lime stabilization. In: Highway Research Record, 139. Washington. Anais...Washington, 61-72.

Faleschini, F., Zanini, M. A., Pellegrino, C. \& Pasinato, S. (2016). Sustainable management and supply of natural and recycled aggregates in a medium-size integrated plant. Waste management, Padova, p. 1-10.

Ferreira, S. R. M. (1999). Colapsibilidade de um solo e seus aspectos relevantes. Revista de Ciência \& Tecnologia., 2, 119 - 136.

Ferreira, S. R. M., Paiva, S. C., Morais, J. J. O. \& Viana, R. B. (2017). Avaliação da expansão de um solo do município de Paulista-PE melhorado com cal. Revista matéria, Recife, 22(1), 1-12.

Figueiredo, S. S. (2011). Estudo da durabilidade de tijolos solo-cal incorporados com resíduos de demolição da construção civil. 2011.107 f. Dissertação (Mestrado) - Universidade Federal de Campina Grande, Campina Grande.

Fuji, L., \& Carvalho, J. C. (2014). Comportamento mecânico de misturas com resíduo de construção e demolição de concreto, cal virgem e hidratada e solo tropical. In: Congresso Brasileiro de Mecânica dos Solos e Engenharia Geotécnica, 17. Goiânia. Anais... Goiânia, p. 1-6.

Goodarzi, A. R., \& Salimi. M. (2015). Stabilization treatment of a dispersive clayey soil using granulated blast furnace slag and basic oxygen furnace slag. Applied Clay Science, Volume 108, pp. 61-69.

Hadzi-Niković, Gordana D. \& Đoković, Ksenija. (2019). Water Retention Parameters and Sediment Dispersivity of the Zemun Loess Plateau (Belgrade, Serbia). Comptes Rendus De L Academie Bulgare Des Sciences, 72(7), 937-946.

Hammes, R. F., Vier, L. C., Rossi, C. T., Dos Santos, R. R., Da Silva, J. M. \& Bock, A. L. (2017). Ensaios de caracterização do solo de RCD da região noroeste do RS. In: Seminário de Iniciação Científica, 25. Rio Grande do Sul. Anais... Rio Grande do Sul, p. 1-5.

Lafayette, K. P. V. (2006). Estudo geológico-geotécnico do processo erosivo em encostas no parque metropolitano Armando Holanda Cavalcanti - Cabo de Santo Agostinho/PE. 391 f. Tese (Doutorado) - Universidade Federal de Pernambuco, Recife.

Lafayette, K. P. V., Cantalice, J. R. B. \& Coutinho, R. Q. (2011). Resistência à erosão em ravinas em latossoloargilo arenoso. Revista Brasileira de Ciência do Solo (Impresso), 35, 2167-2174.

Leite, C. A. V. G., Neto, T. F. P., Aguiar, M. F. P. \& Oliveira, F. H. L. (2016) Análise de melhoramento de solo com brita e resíduos de construção e demolição para camadas de pavimentos no estado do Ceará. Conexões: Ciência e Tecnologia, Fortaleza, 10, 17 - 23.

Macedo, T. F. (2013). Análise do desempenho mecânico da mistura agregado reciclado-solo-fibra-cimento para pavimentação. 157 f. Dissertação (Mestrado) - Universidade de Pernambuco, Recife. 
Research, Society and Development, v. 10, n. 1, e42210111959, 2021 (CC BY 4.0) | ISSN 2525-3409 | DOI: http://dx.doi.org/10.33448/rsd-v10i1.11959

Martins, L. N., Fernandes, F. F. \& Campos, A. M. L. S. (2016). Utilização de resíduo de construção e demolição na estabilização do solo de Iranduba para confecção de tijolo de solo-cimento. In: Congresso Técnico Científico da Engenharia e da Agronomia, 1. Foz do Iguaçu. Anais... Foz do Iguaçu, p. 4-5.

Nascimento, L.H.F. do, Oliveira, V.K. de, Moraes, S. \& Correia, N. (2020). Análise de quebra de grãos de misturas de solo com resíduos de construção civil para camadas de pavimento. Revista Tecnológica, 29(2), 526-540.

Paiva, S. C., Lima, M. A. A., Ferreira, M. G. V. X. \& Ferreira, S. R. M. (2016). Propriedades geotécnicas de um solo expansivo tratado com cal. Revista Matéria (UFRJ). 21, 437 - 449.

Rajesh, T. \& Marimuthu, A. (2015). Geotechnical Characterization of Dispersive Soil Stabilized with Lime and Palm Oil Fuel Ash. Journal of civil Engineering and Environmental Technology. Chennai, 2(8), 713 - 716.

Reis, L. R. M. \& Matos, J. M. E. (2017). Utilização de resíduos da construção e demolição na fabricação de tijolos de solo-cimento. 94 F. Dissertação (mestrado) - Universidade Federal do Piauí, Teresina.

Rocha, G. S. (2018). Efeito da cal na resposta mecânica de um solo residual maduro: análise da resistência à compressão não confinada, permeabilidade, compressibilidade e efeito da cura acelerada na resistência mecânica. 89 f. Dissertação (Mestrado) - Universidade Federal de Viçosa, Viçosa.

Samaniego, R. A. Q. (2015). Estabilização de um solo dispersivo com adição de cal. 171 f. Dissertação (Mestrado) - Universidade Federal do Rio Grande do Sul, Porto Alegre.

Sherard, J. L., Dunningan, L. P. \& Decker, R. S. (1976). Identification and nature of dispersive soils. Journal of the Geotechnical Engineering Division. [S.I.], $102,287-301$

Vakili, A. H., Shojaei, S. I., Salimi, M., Bin Selamat, M. R., \& Farhadi, M. S. (2020). Contact erosional behaviour of foundation of pavement embankment constructed with nanosilica-treated dispersive soils. Soils and Foundations.

Yazdanbakhsh, A. (2018). A bi-level environmental impact assessment framework for comparing construction and demolition waste management strategies. Waste management.. 1-12.

W. Lu, Chen, X., Peng, Y. \& Liu, X. (2018). The effects of green building on construction waste minimization: Triangulating 'big data' with 'thick data'. Waste management. Hong Kong, 79, 142-152.

Zare-Junaghani, N., Mehrnahad, H., \& Torabi-Kaveh, M.. (2019). Assessing Dispersivity and Expansivity of Clay Soils in the South-East of Yazd with Aim of Investigating Correlation between Them. Periodica Polytechnica. Civil Engineering, 63(4), 1112. 